I intended to announce the general equation, without taking the trouble to investigate any possible limitations, but withont denying that limitations may exist. This is the conclusion abont my own meaning to which I came three years ago, when I inverted the question (vol. viii., p. 181) and reduced it to the solution of a functional equation. Mr. Woolhouse cannot have been aware* of this second paper of mine, in which is " required the law of mortality nnder which the table of two lives follows the same law as the table of one life." The demonstrated conclusion is that nothing but Gompertz's law will do. If anyone should happen to know-as was the fact-that I examined the proof of your reprint of my old paper, he will think that $I$ ought to have made an allusion to the recent paper of a more direct character than yours. I am very glad I did not; the consequence has been that we have Mr. Woolhouse's simple algebraical treatment of the subject, which is quite within the grasp of an elementary student.

One thing, however, is wanted: Mr. Woolhouse's solution of the functional equation is good for integer differences of $n$, but the law may vary in an infinite number of ways during the parts of a year. All that is needed is to notice that the unit of time may be any whatsoever. The same caution applies to many cases in which functional equations are employed.

In this last remark I am supposing that Mr. Woolhouse, as is usual, contemplates such a curve of mortality as can be laid down by the help of the numbers living at the end of each year, and by the usual principles of interpolation. These principles contain the assumption that there are no inequalities whose cycle is precisely equal to the interval of time by which values are separated. When the moon's right ascension, obtained from theory for a snccession of noons and midnights, is thence obtained by interpolation at all the intermediate hours, it is assumed that there are no perceptible inequalities which have a cycle of twelve hours of mean time; and the assumption being true, the method answers. It is customary to overlook any inequalities of mortality which ran their comrse within a year, but this neglect will not endure for ever. The changes of season have a much more sensible effect on health and life than the rotation of the earth has on the moon's motion. The time may come when the trigonometrical considerations which enter into the complete solution of the functional equation may be called into nse; and the number living at the age $x$ may be a function of the sun's right ascension, and perhaps of the moon's right ascension also. In the mean time the limited solution of the functional equation, when the true grounds of its practical sufficiency are pointed out, may be made a useful lesson to those who are beginning the subject.

$$
\text { I am, yours very truly, }
$$

April 24th, 1862.

A. DE MORGAN.

\title{
ANOTHER DEMONSTRATION OF THE EXPRESSIONS FOR THE VALUE OF SINGLE AND ANNUAL PREMTUMS.
}

To the Editor of the Assurance Magazine.

SIn,-Can you make room for yet another determination of the single and annual preminms for assurance?

* Mr. Woolhonse was not aware of it when he wrote,-En, A. M. 
An assurance of $\mathfrak{E 1}$ is to be effected on $(x)$, for which the single premium is $\mathbf{A}_{x}$. This preminm is not to be paid now, however, but is to remain a debt upon the policy till the latter becomes a claim; and an equitable consideration is to be paid annually, during the life of $(x)$, for its forbearance. Now, the consideration for forbearance of $£ 1$ for a year being $1-v$, that for forbearance of $\mathrm{A}_{x}$ for the same time will be $(1-v) \mathrm{A}_{x}$; and this, therefore, will be the annual payment to be made during the life of $(x)$.

Hence the total consideration to be made for the assurance of $£ 1$ will be, first, a payment at the end of the year of death of $A_{x}$, the sum forborne, the present value of which is $A_{x} \times A_{x}$, or $A_{x}^{2}$; and, second, an annual payment of $(1-v) \mathrm{A}_{x}$, the present value of which is $(1-v) a_{x}^{\prime} \mathrm{A}_{x}$, where $a_{x}^{\prime}$ denotes the present value of an annuity due of $£ 1$ on $(x)$.

Therefore, equating present values,

$$
A_{x}=A_{x}^{2}+(1-v) a_{x}^{\prime} A_{x}
$$

whence, dividing by $\mathbf{A}_{x}$ and transposing,

$$
\mathrm{A}_{x}=1-(1-v) a_{x}^{\prime}
$$

Since the claims arising by the death of $(x)$ are satisfied by a payment from the Office of $1-A_{x}$, it follows that the foregoing transaction resolves itself into an assurance of $1-\mathbf{A}_{x}$, paid for by the annual premium $(1-v) \Lambda_{x^{*}}$ Hence, if $\pi_{x}$ denote the annual premium for an assurance of $\mathfrak{E} 1$, we have

$$
\begin{gathered}
1-A_{x}: 1::(1-v) A_{x}: \pi_{x} \\
\therefore \pi_{x}=\frac{(1-v) A_{x}}{1-A_{x}}
\end{gathered}
$$

a known form, which reduces to the more usual form by substitution for $A_{x}$ in terms of $a_{x}^{\prime}$

$$
\text { I am, Sir, }
$$

Your most obedient servant,
7, St. Paul's Villas, Camden Town,
P. GRAY.
4 ith June, 1862. 